\title{
On the Social Shaping of Quantum Technologies: An Analysis of Emerging Expectations Through Grant Proposals from 2002-2020
}

\author{
Tara M. Roberson ${ }^{1}$ (D)
}

Accepted: 17 February 2021 / Published online: 18 March 2021

(C) The Author(s) 2021

\begin{abstract}
The term 'quantum technology' was first popularised by an Australian physicist in the mid-1990s. These technologies make use of the properties of quantum physics and are being developed and invested across the world, yet this emerging technology is understudied in science and technology studies. This article investigates the emergence of the notion of 'quantum technologies' and examines the expectations shaping this field through an analysis of research grants funded by a national research funder, the Australian Research Council between 2002 and 2020. I examine how 'quantum technology' and 'quantum computing' have come to dominate claims and expectations surrounding research in quantum science. These expectations do more than inform the scientific goals of the field. They also provide an overarching, uniting rhetoric for individual projects and people and shape the uses imagined for quantum technologies. This analysis shows how claims for this emerging technology draw on 'breakthrough' metaphors to engage researchers and marshal investment and concludes by highlighting the need for increased clarity regarding expectations for quantum technologies.
\end{abstract}

Keywords Expectations $\cdot$ Hype $\cdot$ Quantum technology $\cdot$ Emerging technology

Tara M. Roberson

t.roberson@uq.edu.au

1 ARC Centre of Excellence for Engineered Quantum Systems, School of Mathematics and Physics, University of Queensland, Brisbane, QLD, Australia 


\section{Introducing Quantum Technologies}

"I am in no doubt that the future of high technology is quantum technology. The idea that the physical world can be manipulated at the level of the quantum is powerful stimulus to the imagination of physicists and engineers the world over. It is hard to say just where these ideas will lead us."

(Milburn 1997: 179)

As Guston (2012) recounts in an earlier issue of Minerva, stories can quickly illustrate the unpredictability of science. Guston points us to Michael Polanyi's account of how a booth full of researchers could think of no technical application of Einstein's theory of relativity despite, a few months later, an application being explosively revealed via the first atomic bomb. For a milder example, you might look to how the introduction of a mechanical harvester and tomato hybrid changed the Californian tomato industry within the span of just five years with an estimated 32,000 jobs lost to the gain of a few (Winner 1980). Ask again for a happier example and perhaps you might consider the invention of the transistor in Bell Labs, originally intended for use amplifying telephone signals but today the starting point for electronic devices worldwide (NOKIA Bell Labs 2019). These examples indicate how a seemingly neutral or benign advancement in research can have far-reaching implications.

Polanyi's contention that you cannot guide science towards a specific purpose or anticipate the future consequences of research is reminiscent of Vannevar Bush's (1945) belief that scientists should be left alone to determine the course of their own research and be untroubled by practical concerns or social imperatives. Yet, since this time, support for this hands-off approach seems to have eroded with a desire to see science and technology consciously contributing to societal issues and grand challenges now foregrounded (Cagnin et al. 2012). With this shift comes a need to better anticipate the outcomes of research to prevent us "blundering into synthetic biology, nanotechnologies, and geoengineering as we blundered into the atomic age" (Guston 2012: 13). How might this anticipatory work factor into an emerging age of second-generation quantum technology?

New technologies can have significant implications for our social settings. These technologies are, in turn, socially shaped. That is to say, technologies are "generated by people operating in social contexts... and at particular historical moments, all of which shape the imagination of what needs technology might meet and in what settings it might be employed" (Dourish and Bell 2014: 51). While there has been some analysis of national strategies for quantum (Roberson et al. 2020), little attention has been paid to rhetoric on the level of individual researchers and laboratories. Consequently, there is currently a lack of discussion as to how technical uses of quantum science might play out in social spheres. This article aims to begin addressing this gap while investigating the emergence of the notion of 'quantum technology' in the mid-1990s.

Here, I examine the social shaping of quantum technologies and recognise the role of imagination and anticipation in organising academic research as well as 
in setting government and industry agendas worldwide (Jasanoff and Kim 2015). Understanding this social shaping is crucial if we are to interrogate the course set for future use of quantum technologies (Guston 2012). These technologies may be applied in a range of areas ranging from health to finance, telecommunications through to mining and defence. The consequences of their use are largely unknown and worth further investigation. As an example, consider the central role that cryptography plays in making essential services, such as digital payments and secure communication, possible. Quantum technology may be able to further protect this information. However, concerns have already been raised over whether quantum technology might render current forms of cryptography vulnerable to a so-called 'quantum attack' (de Wolf 2017; DiVincenzo 2017).

In this context, I interrogate the early shaping of quantum technologies with grant proposals written by the Australian quantum physics researchers. I examine the expectations they articulate for these technologies to grant funders-including the Australian Research Council and the research council's audience of politicians and policymakers - and their peers and grant assessors from the physical sciences.

In this paper, I provide a brief history of quantum technology, including the current state of public funding and an indication of commercial activity in this space. Then, I present the conceptual framework for this research. Next, I outline my approach to this analysis, which is informed by rhetorical analysis. The goal of this type of analysis is understanding how language responds to and influences events (Ploeger 2002). I examine how the language of quantum science has shaped and positioned 'quantum technology' by analysing texts from nationally funded grants between 2002 and 2020 in Australia, which was an early focal point for research in quantum science. The findings of this article represent a first step in discourse analysis for quantum science and technology and, in line with this, I suggest avenues for additional investigation.

\section{An Introduction to Quantum Technology}

Quantum technologies are devices and products that make use of the properties of quantum physics, or the study of how the world works on extremely small scales. Applications of quantum science are being developed across the world through significant financial support from governments and corporations. Funded initiatives include: the UK Quantum Hub Network (over USD \$1 billion across ten years), the United States National Quantum Initiative (USD\$1.2 billion over five years), the European Union Flagship Quantum Program (over USD \$1 billion over ten years), and China's reported \$USD10 billion investment in a quantum lab based in Hefei (Bloomberg 2018; CSIRO 2020). This is in addition to substantial sums invested by private companies, including Microsoft, Google, IBM, and Intel and a growing cohort of smaller start-up companies (Gibney 2019). Alongside this investment, national strategies have been launched to help individual regions or countries to consolidate their position in the emerging quantum economy.

The growing emphasis on quantum technologies increased in national and commercial settings after the launch of a quantum satellite by China in 2017 and 
the realisation of an important milestone in quantum computing by Google in 2019. While the challenges for quantum technologies may appear to be purely technical, these technologies also pose questions in terms of their social and ethical implications (EPSRC 2018). For instance, a large-scale quantum computer might break a common form of encryption-which protects information from hackers and allows for everyday digital communication and commerce-in as little as eight hours (MIT Emerging Technology 2019).

In Australia, research in quantum science and technology has been underway in the country in the form of theoretical and experimental work for more than two decades (Roberson and White 2019). At the time of writing, Australia's national research organisation, the Commonwealth Scientific and Industrial Research Organisation (CSIRO), has published a national quantum technology roadmap to further this research and development (CSIRO 2020). The CSIRO's consultation process identified risks that could affect the development of these emerging technologies. Among those risks was the danger of 'unrealistic expectations'. A discussion paper published during the process of creating the roadmap noted: "speculative bubbles may form based on misinformation and unrealistic expectations, damaging long term investment strategies". To address this, the writers recommend communication campaigns that could "de-mystify and manage expectations surrounding quantum technology" for industry and the 'general public' (CSIRO 2019: 36).

Research in quantum science was conducted by individuals and research laboratories in Australia during the 1980s and 1990s. But, in the 2000s, research in this field began a new, coordinated approach with launch of a Centre of Excellence program by national research funder the Australian Research Council (Roberson and White 2019). This program aimed to scale up research efforts by uniting individual efforts at universities through national virtual centres, which run for seven years per successful grant. At the same time as these more coordinated initiatives were funded, the Australian Research Council also invested in other complimentary projects through grants known as 'Discovery Projects' (multiyear, lab-scale grants), industry-focused linkage grants, and individual fellowships.

This history of national funding for quantum science in Australia means that researchers' visions for the field can be investigated by analysing the claims put forward in grant proposals. As essentially persuasive texts, these proposals are written with the aim of convincing grant funders and academic peers of the worthiness of research projects (Myers 1990; Connor and Mauranen 1999). Recent work on this genre has investigated how researchers use specific structures and rhetoric to cope with risk (Barlösius 2018), described newness in research (Barlösius 2019), and examined how researchers frame unconventional projects and used conventional language (Philipps and Weißenborn 2019). In this research article, I present an analysis of grants written within a specific subset of quantum physics for an Australian funding body. I interrogate the framing of these research proposals to understand how researchers communicate about 'quantum technology' as an original area of research (Barlösius 2019) with applied outcomes (Serrano Velarde 2018; Laudel 2006). 


\section{Conceptual Framework}

Imagination is a crucial ingredient for scientific and technological enterprise (van Lente 1993; te Kulve et al. 2013). This imagining of the future of science and technology is not simply a matter of science fiction (Fujimura 2003). In fact, the imaginative work done by science and technology actors helps to organise essential scientific practice as well as the communities these actors operate within. Science and technology actors can include researchers, policymakers, and funders. These actors craft visions of the future and identify the expectations that inform those futures, often by making promises or highlighting concerns to motivate change and drive momentum (Tutton 2011). Imagination also unites members of a community through shared perceptions of futures that should (or should not) be realised (Jasanoff and Kim 2015).

When researchers bid for funding, they often look to the future and make promises for the application or translation of their research and make claims for research originality (Barlösius 2019). These promises may or may not be fulfilled within the timeframe set, if at all (Brown 2003). In this article, the promises in question are centred on claims for quantum physics and quantum technologies. The mix of fundamental and applied research presents an interesting question of how quantum researchers make claims of originality for their work. While physics research proposals might characterise research novelty in terms of addressing fundamental questions, more applied disciplines tend to focus on creating something new (Barlösius 2019). These types of claims are more frequently found within the disciplines of computer science and engineering, which tend towards practical terms and solutions. These disciplines use verbs such as 'develop', 'construct', and 'build'. These claims convey how researchers conceptualise and prioritise the outcomes of their work in order to persuade funders that their work is worth support.

Jasanoff and Kim capture future-bidding work within their concept of 'sociotechnical imaginaries' where imaginaries "at once describe attainable futures and prescribe futures that states believe ought to be attained" (2009: 120). The concept of sociotechnical imaginaries describes how we witness the prototyping of possible futures where initial expectations and promises are set high to begin the agendasetting process (Geels and Smit 2000) (Apreda et al. 2014). This construction of potential futures not only serves to attract interest, funding, and evoke excitement; it can also encourage people to accept emerging technology and new research (Nerlich et al. 2009). It also provides a prompt for 'opening up' discussions on science and technology in the making.

Expectations are statements about future conditions and developments (Borup et al. 2006; Brown 2003). They reference assumptions about how the future should be and how likely this change is (Williams 2006). Expectations are the product of the futures put forward by science and technology actors in the course of strategic communication and dedicated promotional work. As such, they are enduring features of technoscientific work (Konrad et al. 2017) which invite heighted expectations and increase the chance of creating disillusionment when promises are not fulfilled. 
The dilemma of raised expectations and potential disillusionment is a familiar conundrum for innovation and science and technology studies research, which is sometimes simply referred to as 'hype'. The industry-based Gartner Hype Cycle also charts this process as part of the five stages of hype. The five stages are: the innovation trigger, the peak of inflated expectations, the trough of disillusionment, the slope of enlightenment, and the plateau of productivity (Gartner 2015). The Gartner Hype Cycle naturalises the stage of disillusionment by incorporating disappointment and the downturn of excitement within the process of innovation (Joly 2010). As a consequence, the cycle avoids any need to account for the ramifications of disillusionment, not just for the people or organisation creating a product but also for the publics and stakeholders who have been promised a solution.

Hype involves exaggeration or sensationalisation of 'pure' research. It is implicit in the research process in that it helps stimulate financial and social support (Nerlich and McLeod 2016; Hellsten and Nerlich 2008). Because of this, hype seems almost inevitable in the communication of science and technology. Indeed, science writer and journalist Tim Radford argues that the act of selecting one topic or focus over another is an act of hype. He writes: "I have chosen this finding rather than that, or the other, so it must be more important, more compelling, more exciting. I select, therefore I hype" (Radford 2009: 147).

Raising expectations and engaging in hype is a risky process where the chance to build anticipation and support for, as an example, stem cell treatment may come at the cost of lost public trust (or increased cynicism and fatigue) if the treatment does not eventuate (Petersen et al. 2017). Brown reflects on this dynamic within his work on the sociology of expectations in which hype mobilises the future into the present through articulating a vision of the future and making, almost inevitably exaggerated, promises in order to command interest (Brown 2003). While hype is a means of securing the social change necessary for technological revolution because it "communicate[s] as yet unimagined possibilities" (Ritter 2010), it also invites reactions from the publics and stakeholders who are the audience of hype (Roberson 2020). This is both an opportunity and problem for quantum science and technology, depending on how expectations were (and are) managed over the course of the field's development in Australia and further afield.

To investigate those expectations for emerging quantum technologies, I present a rhetorical analysis of how the field of quantum technologies evolved in Australia. Rhetoric plays a key role in this space as it influences how people relate to the world and to each other (Fuller and Collier 2004). It both catalyses engagement with science and technology and helps analyse that engagement (Gross 1994). In this instance, rhetorical analysis provides a situated account of how the language of quantum technologies has emerged.

\section{Method}

The most complete database for Australian quantum science research grants is hosted by the Australian Research Council (ARC) on the ARC Data Portal under 'Grant Search'. This grant search system allows anyone to find the public details of 
research projects that have been successful in attaining funding from the Australian Research Council since 2001. A search within this system for research grants focused on 'quantum' returns over 900 entries and spans the years of 2002 through to 2020. These results were checked for relevance (i.e. I confirmed that the research was concerned with quantum physics). After this step, 705 grants remained.

The results from the Australia Research Council system were exported into comma separated value files, which contained various information including: grant number, host organisation, lead investigator, grant summary, field of research code, and amount funded. For this qualitative analysis of the language of quantum research in Australia, the grant summary was of interest as the summary outlines the core arguments for why a project should funded (i.e. potential outcomes and relevance to national interests).

As has been previously argued for the fields of biotechnology and nanotechnology, naming the focus of a field has a performative effect. In other words, a "new technology exists because we name it" (Joly 2010: 3). In the first stage of analysis ("Competing Terms"), I examined the use of the term 'quantum technology' in the summary text of grants funded by the Australian Research Council. I compared the use of the term with competing and similar terms, such as 'quantum computer', 'quantum device', and 'quantum machine'. I searched through quantum science research grants exported from the Australian Research Council database for grant summaries that used the terms: quantum technolog* (technologies, technology); quantum comput* (computer; computing; etc); quantum device* (device, devices); and quantum machine* (machine, machines) to determine how and when they were used across the eighteen years of grants made available by the Australian Research Council.

In the second stage of analysis ("Physics Becomes Engineering: Themes of Quantum Research in Australia"), I used an automated content analysis software called Leximancer. This approach allows a researcher to automate grouping of text-gathered from large bodies of work-into concept lists, isolate consistent metaphors, and identify relationships within the texts. By using the original material and not being dependent on the interpretation of an analyst, Leximancer achieves a high-level of reliability and repeatability (Smith and Humphreys 2006). The software groups sentences into blocks to generate its text-based statistics, which include rank-ordered concept lists to indicate the strength of relationships between tags and concepts (van Vuuren et al. 2014). As well as generating these statistics, Leximancer represents concepts from the text in a two-dimensional map. Each Leximancer concept map shows the main concepts that occur within the text. These are shown by the black text and grey dots. The grey links show connections between the concepts. The concepts are clustered within coloured circles or themes on the map. The colour of theme is designated by heat mapping to convey importance. The most important theme appears in red, the second appears in orange, and so on based on the colour wheel. Each theme takes its name (the text which is the same colour as the circle) from the most frequent and connected concept within the circle. This aspect of the analysis focused on how quantum technology was represented within research projects and identified central metaphors used to describe Australia's participation in the race to realise these technical applications. 


\section{Competing Terms}

Novel technologies exist, first, in the imaginings, expectations, and visions that shape their potential (Borup et al. 2006). The phrase 'quantum technology' was first popularised in a book written by Australian physicist Gerard Milburn. Called 'Quantum Technology' in the 1996 version published by Allen \& Unwin in Australia and 'Schrodinger's Machines: The Quantum Technology Reshaping Everyday Life' in the 1997 version published by W. H. Freeman in the United States of America, the book defines quantum technology as "a technology which manipulates quantum probability amplitudes directly" (Milburn 1997: xvi). The first title "Quantum Technology' united two-seemingly incompatible_-words: quantum, the domain of researchers, and technology, the domain of engineers.

As Davies notes in the foreword of Milburn's book, "What the public perceived as primarily a set of revolutionary speculations about the nature of reality, professional physicists and engineers regarded as a means to make new devices and handsome profits" (1997: vi). Perhaps, the joint concept of quantum technology was not too strange for people within those fields. ${ }^{1}$

The initial definition of quantum technology was expanded upon in 2003 by Milburn and fellow physicist Jonathan Dowling in an article published by the United Kingdom's Royal Society. In this article, Dowling and Milburn define the objective of the new field of quantum technology as "to deliver useful devices and processes that are based on quantum principles" (Dowling and Milburn 2003: 1656). These technologies are part of a second quantum revolution. Where the 'first quantum revolution' helped establish understanding of the rules that govern quantum physics, the 'second quantum revolution' would use this understanding to develop new technologies that fully use quantum effects.

The second quantum revolution will "be responsible for most of the key physical technological advances in the 21st century" and yet, as Dowling and Milburn note, in the year 2003 it was fair to suggest that researchers had only "begun to take the first halting steps" towards realising quantum technologies (Dowling and Milburn 2003: 1671). They contend that an enormous, focused effort would be required to progress towards potential commercial application and that the key challenges for progressing in this research was amending a lack of "no dedicated effort in quantum technology as such" and an official definition for the field.

At the same time as this broader discussion was starting around the discipline of quantum technology, researchers across the world were working on theoretical research and experiments in the laboratory which have come to define the trajectory of quantum science. In this article, I consider a small sample of grants, which represent Australian research in quantum, to map how the language of quantum technology evolved.

The peaks and troughs of the graph in Fig. I are indicative of how the terms were used in grants between 2002 and 2020. Between 2002 and 2020, 91 projects

\footnotetext{
1 Discussions on possible applications of quantum science preceded Milburn's book. For example, Robert Bate's (1986) piece in the Scientific American on a quantum semiconductor device.
} 
Terms used in Australian Research Council-funded quantum research proposals, 2002-2020

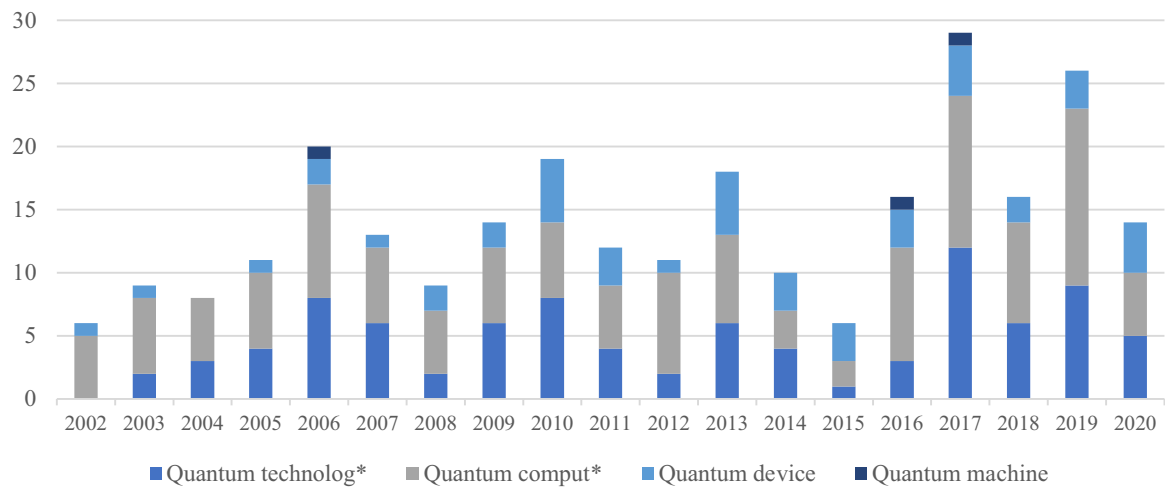

Fig. I Terms used in quantum research grants

were funded which mentioned 'quantum technology'. In comparison, 127 projects referred to 'quantum computer', three referred to 'quantum machine', and 46 referred to 'quantum device'. This count reflects any project that used these terms, including multiple projects which referred to two or more terms within the grant summary (i.e. 'quantum technology', 'quantum device', and 'quantum machine').

These terms were not the sole descriptors related to applications of quantum science. Further close reading of the grant summaries revealed 25 projects referred to 'quantum communication' (a process that exchanges information which is protected by quantum effects), four referred to 'quantum key distribution' (a quantum-based approach to encryption), eight referred to 'quantum control' (error correction within technologies that use quantum effects), nine referred to 'quantum metrology' (high sensitive measurements using quantum theory), and 12 referred to 'quantum measurement' (manipulating a physical system in quantum where measuring a quantum system causes it to change). Other projects mentioned the creation of 'new technology' or 'devices' and some specified uses in areas that included: medical diagnosis, solar energy harvesting, and cybersecurity.

Overall, only $31 \%$ of the grants exported from the Australian Research Council database did not mention some form of technical application or product that might be produced through investment in quantum science research projects. This indicates that, at least as far as funded research grants are concerned, the predominant language of the 'second quantum revolution' is concerned with technical advancement and devices and, usually, these are related to 'quantum technology' and 'quantum computing'.

The coining of these terms is indicative of the expectations building around quantum science. These expectations play a powerful role in shaping the future as they pre-suppose something will happen and, through this presupposition, bring the future into being (Schyfter and Calvert 2015). In this way, they both shape the future and the present; specifically, they affect the ability of a science and technology actor to deliver on promises by helping them access material and social support, such as 
funding, networks, and other resources. Because predicting the future-particularly the future of research which has not yet been done-is risky, the expectations produced by actors need to be sufficiently broad so as to have "interpretive flexibility" (Eames et al. 2006: 1). This means that advocates for the field must resist the temptation to narrowly define promises or outcomes so that new developments can be more easily incorporated into the overall guiding vision.

In this context, actors manage expectations for their work, build narratives, and begin cycles of legitimation, expectations, social support, funding, development, and disappointment (Apreda et al. 2014; Birch et al. 2012). These cycles undermine normatively linear and deterministic accounts of technological development by demonstrating that complex factors-including agenda building by making purposeful promises and establishing organisational and personal influence-can determine the course of the future. One area that deserves further investigation is how the terms 'quantum technology' and 'quantum computing' interact. Do these terms operate separately, in coordination, or do they compete? Further research into more public expectations and perspectives of this area might shed light on this question.

\section{Physics Research Becomes Engineering: Themes of Quantum Research in Australia}

In the second stage of analysis, the grants were analysed using the concept analysis software Leximancer to identify overarching themes and the concepts. This automated concept analysis generated the concept map in Fig. II, which featured six themes (represented by the large circles) at $60 \%$ theme size. This theme size reduces the number of themes to the top-level concepts within a text. Leximancer 'heat-maps' themes to indicate importance, starting with red. 'Quantum' was therefore the most important theme, followed by technology, physics, devices, properties, and structure. I explore the application-centric aspects of these themes in detail now, using samples of text from the grant summaries.

Application-focused grant proposals that specifically focused on 'quantum technology', 'quantum computing', 'quantum devices', and 'quantum machines' were concentrated in the Leximancer concept map within two themes: technology and devices. This is shown in Fig. II by the red tags (i.e. "quantum-machine_quantum_ machine" and "Quantum-technology_quantum_technolg_"). The tags reflect how each grant was individually identified during the close read conducted in the first stage of analysis, before being uploaded into Leximancer. The majority of grants that referred to quantum machines and quantum technology were located in the technology theme on the Leximancer map. Meanwhile, grants referring to quantum computing were clustered just outside of the overlap between the technology and devices themes and grants referring to quantum devices were located further within the devices theme.

The technology theme shows these grants discussed potential applications of quantum science and included references to the concepts that included: research, Australia, development, science, future, and computing. Text from this theme was deeply concerned with the benefits of funding research in quantum technologies 


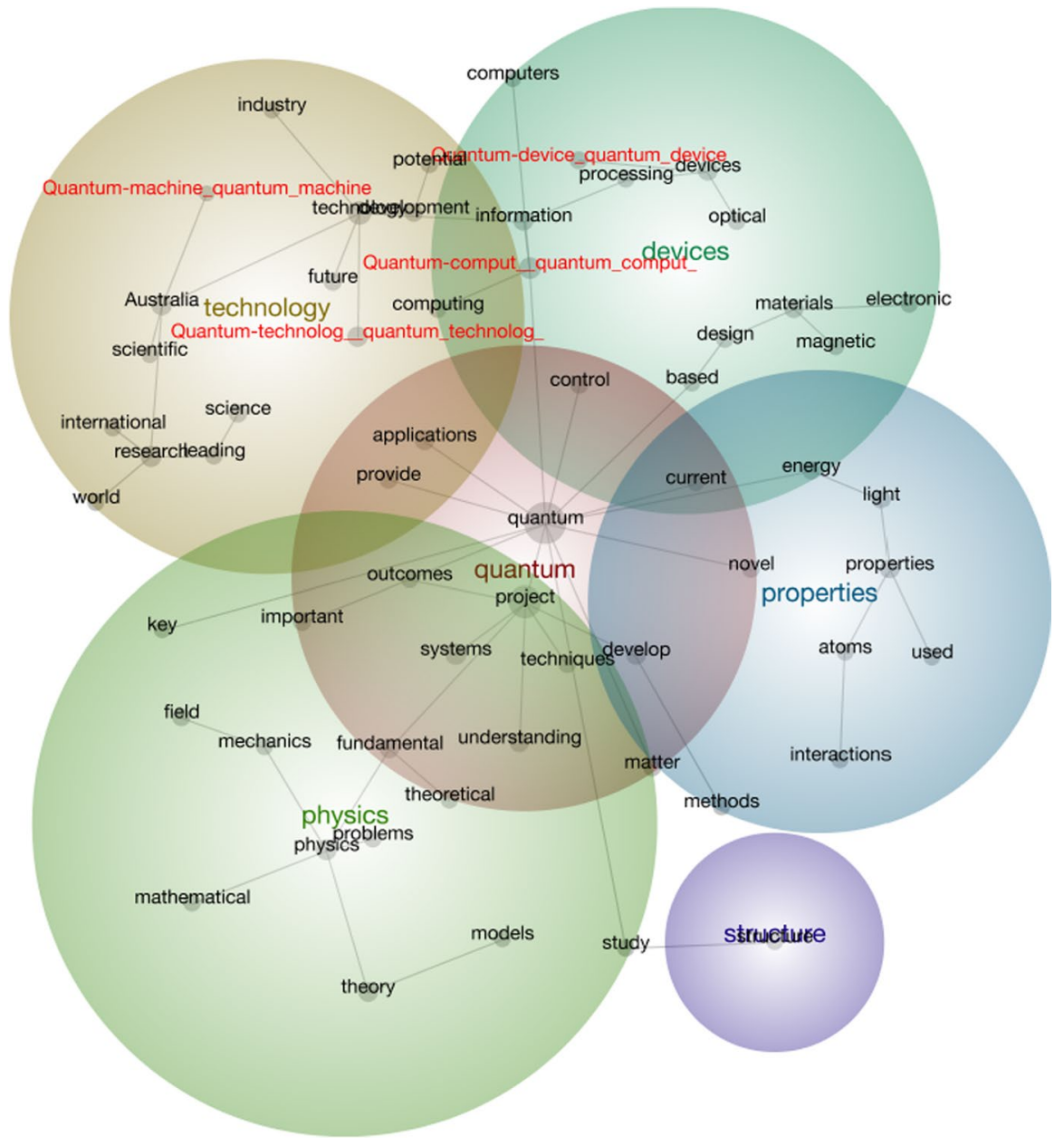

Fig. II Leximancer concept map of quantum grants funded by the Australian Research Council

for Australia. It also referred to the possible outcomes of this research for fields that included health, biomedical research, and weather modelling.

The project will expand the boundaries of the quantum realm by building the largest quantum objects ever assembled and put them to work in computing and cryptography. These quantum devices will help Australia lead the race for future information technologies. [Discovery Project, 2013]

This proposal will provide a significant breakthrough by develop a new class of ultra low disorder 'quantum dot transistors' that will be of benefit to Australia's ongoing efforts in semiconductor nanotechnology and quan- 
tum information science, allowing us to play a role in the future development of nanoscale and quantum electronics. [Discovery Project, 2007]

Meanwhile, the devices theme addressed concepts such as: information, materials, and control. Text in this theme was concerned with discovering the knowledge, techniques, and materials that would support the creation of quantum technologies.

This is expected to lead to greater control over systems, demanded by quantum computers and nano devices, like next generation computer chips. [Discovery Early Career Research Award, 2017]

The ability to directly control interactions and measure correlations in quantum matter at the atomic scale could provide the most direct method to date to tailor the properties of an entirely new class of technologically relevant quantum materials. The peculiar electronic and magnetic properties of such materials put them in a leading position to revolutionise energy, information, and communication technologies. [Discovery Project, 2018]

The claims made around delivering quantum technologies in the grants analysed here diverged from the standard claims for originality in physics research (Barlösius 2019), although this conception of originality was evident within the Australian Research Council grants that were concerned with 'pure' quantum science (for instance, text from within the physics and properties themes in Fig. II).

This will provide deep insight into properties of complex classical and quantum waves, and new avenues for fine control of diverse light, matter, and mixed light-matter systems. [Text from the physics theme - ARC Future Fellowship, 2014]

Our recent publications have proven that this novel approach can yield new insight into the interaction of light with matter. [Text from the properties theme - Discovery Project, 2002]

Instead, claims for application (called 'a model of temporal originality' by Barlösius 2019) focused on producing something (technology) new that does not yet exist. In this analysis the technology theme found researchers promising to 'develop' new quantum dot transistors and 'build' the largest quantum objects ever assembled. As usage of terms like 'quantum technology' and 'quantum computer' progressed through the years (see Fig. I), the use of these practical and applied phrases continues. Researchers now aim to 'build' a mechanical quantum memory and a computer based on quantum physics and 'create' a new platform for superconducting device development.

Centre for Quantum Computer Technology. Development of a quantum computer $(Q C)$ for massively parallel computing is one of the major challenges in science and engineering this century. Since 2000 the Centre has achieved two major breakthroughs in this field: constructing the key functional element of a silicon solid-state QC; and co-inventing a scheme for efficient linear optics QC. The proposed CoE aims to align these two nationally co-ordinated 
research programs with the world's existing computer and IT industries to realise a fault-tolerant multiple qubit quantum processor with integrated control and qubit chips, and develop a scaleable optical quantum processor providing significant economic benefit to Australia. [ARC Centres of Excellence, 2003]

Quantum measurements are the principal means by which we gain access to and characterise the quantum world. The new, better and easier measurements that should result from this project will greatly advance quantum technologies. Specifically, they should allow for more efficient characterisation of quantum computers and enable us to engineer the ultimate quantum sensors, enhance mineral prospecting; and make building a quantum computer practical. [Discovery Early Career Research Award 2017]

This shift towards a more applied, engineering-focused language might reflect wider adoption of the phrase 'quantum technology' as the focus of the field partially redirects away from fundamental research towards technical application.

\section{'Transcendent', 'Breakthrough' Technologies}

The descriptions of quantum technologies within the grant proposals made liberal use of 'breakthrough' and 'revolutionary' metaphors (Nerlich 2009; Horst 2007). The 'breakthrough' metaphor has a distinctly military-then turned scientific- - history and has come to be the "most powerfully future oriented metaphor within the current repertoire of science and science journalism” (Brown 2000: 89).

References to technology within the text included generic claims concerned with: "breakthrough technology", "the quantum technological revolution", "twenty first century technology", "the emerging market of quantum technology", and the "quantum revolution, hailed as the next major step in societal evolution, providing breakthroughs in modern technology". This revolution was envisioned as impacting on the fields of metrology, data storage, security, communication, finance, and medicine.

When it came to quantum computers, researchers made broad statements that related quantum computing to current use of classical computing. For instance, that "computers are the foundation of our digital economy" and quantum computers would "transcend traditional computing". Applications included the: "factoring of large numbers or searching unordered databased run with significantly fewer operations" and use in "pharmaceutical design, finance, and national security" as well as "gene sequencing and weather modelling [sic]".

Breakthrough and revolution each fit within what Nerlich (2009) defines as an 'ascent' metaphor. Ascent metaphors frame the progress of science within the context of a 'race' or 'journey' frame. They are positive metaphors which imply advancement when employed by scientists and other science and technology actors. In the case of quantum technology, the 'race' or competition frame has been prevalent inside and outside of the scientific community since the term was first coined 
in the 1990s. What started as a technical and scientific competition has shifted into a context of national security and economic gain with quantum computing, in particular, sometimes referred to as the "new 'race to the moon' pursued with national pride and tremendous investment" (Moller and Vuik 2017: 253). The following excerpt from a grant summary demonstrates this adoption of the race framework with a researcher using a combination of metaphors in contending that investment in quantum would have a:

multitude of benefits for Australia, not only because of the economic potential of deuterium, but because it will see a new generation of Australian researchers trained in multidisciplinary cutting-edge research while addressing several areas of national priority, including breakthrough sciences, and development of frontier technologies, and thereby creating new opportunities for industry. [Discovery Project, 2008]

This example combines both kinds of originality claims by encouraging expectations that this research will answer fundamental research questions and produce new technologies. The researcher also adopts a frontier-based metaphor, which draws on notions of a pioneering spirit and positions quantum science as an unexplored land with the potentially significant opportunities. This metaphor emphasises the notion of scientific progress as being the "key to security as a nation, to our better health, to more jobs, to higher standards of living, to cultural progress" (Greenberg 2001: 57). All of which dovetails with need for nation-states to compete in this space to secure their position or advantage in emerging technology development. In the present day, the quantum race is occurring between research laboratories and centres, nation-states, start-ups, and corporations. The examples considered here represent but a small slice of this competition-focused rhetoric within the Australian research community.

\section{The Role of Technoscientific Promises}

Grant proposals play a vital role in research. As persuasive texts, these proposals work to convince funders and peer reviewers that a project is worth substantial investment. In the case of the successful grants analysed here, these proposals convinced a national funding body - the Australian Research Council and its academic grant assessors - that these projects should be supported by public funds, sometimes over considerable time periods (i.e. seven years investment for each Centre of Excellence funded).

It is important to acknowledge this persuasive context when critically examining the promises of grants. In this instance, those promises are contained within highlevel summaries available through the research council website. This analysis is limited by the information available through that website and it is impossible to know whether those promises were moderated in the full grant. Despite this limitation, the rhetorical claims made in these grants do tell us something of how the Australian quantum research community has shaped scientific practice as well as potential new technologies that are enabled by the properties of quantum physics. 
Technoscientific promises are key to mobilising research, investment, and the circulation of ideas and building up resources (Joly 2010). To achieve these goals for a given research field or topic, these promises must demonstrate a link to a given problem, then provide 'good' reasons for agreeing to a particular option and establish solid credibility which demonstrates why the actors making promises are best suited to deliver on their stated goals. Similarly, Borup et al. (2006) show how novel technologies emerge first in imaginings, expectations (promises) and visions that inform their future shape and use.

Within the high-level language used in the grant summaries analysed here, few specific problems were identified although grant writers anticipated that emerging quantum technologies would influence a range of fields. The creation of technology in those fields - as a means of advancing technical ability and consequently progressing practice-was presented as a means within itself. This technology creation also reckoned on creating economic benefit (perhaps in answer to an assumed need for diversified income and industry) for Australia through intellectual property, patent creation, and commercialisation.

Problematisation - or the creation of a problem which research is best equipped to solve-in this example of quantum technologies in Australia has so far remained general. Additionally, reasons for agreeing to lock-in to a quantum-based future has so far relied on ideals of technological progress that ensures economic and societal benefits and some inference of urgency. For instance, within the fifth theme of 'research' in the Leximancer concept map, urgency is alluded to in relation to placing Australia at the lead, or at the centre, of research and commercialisation in a "strategically important new generation technology" [Discovery Project, 2007].

Promises must also be seen as credible. In part, this credibility is generated by specialisation (the creation of experts in a field). Coining the name of a new technology also plays a powerful role and competing terms such as 'quantum technology' and 'quantum computing' have been in some form of competition for attention over the past eighteen plus years in this context while alternatives, such as 'quantum device' and 'quantum machine' have been rarely used.

The persuasive use of these promises in the grant process is inevitable, while hype, in a broader sense of sociology of expectations, plays a key role in shaping investment and technology change (Apreda et al. 2014). The hype of quantum technologies in this analysis is related to technological applications and economic benefit with quantum technologies anticipated to have use in health, communication, national security, finance and so on. These broad aspirations imply that these technologies are a catch-all solution for societal issues with little contextualised information. It would be interesting to expand upon this view of quantum technologies (which is narrowly located in terms of a specific public - a research funder) through more public-facing media to examine whether these expectations and visions for quantum technology are further developed.

The predominant themes within the grants correspond to the notion of progress as we experience it today and is wedded to a belief that science and and technology are the key to solving social problems (Konrad et al. 2017). There is a "palpable sense that things could be (all) right if we leverage new spaces of opportunity" and reconfigure what is possible (Adams et al. 2009: 246). Some of these expectations 
and visions for these solutions will inevitably underperform and may come at a price (Arribas-Ayllon et al. 2010; Apreda et al. 2014). Despite this, "it remains difficult to see whether-this time-our high expectations might be justifiably warranted" (Borup et al. 2006: 290). Expectations play an evaluative role in this context by functioning as informal, de facto assessments of emerging technologies (te Kulve et al. 2013; Rip 2010), which influence how science and technology are valued in a community and shape how people make sense of developments that are not yet concrete (Konrad et al. 2017).

A lack of public clarity regarding concrete expectations for quantum technologies has yet prevented specific engagement around societal impact. So far, in the United Kingdom, responsible innovation has been adopted as one framework for creating the 'right' social context for quantum technologies (EPSRC 2014). Yet, the program has so far "largely fail[ed] to define tangible measures for the implementation of such as process" (Coenen and Grunwald 2017: 282). Engagement with wider publics for the United States' strategy has largely been relegated to 'dissemination' of developments "as appropriate" (USA 2018: 7). In another example from Canada, public dialogue is remarkable only in its absence with the sole reference to communication made by a researcher arguing for "more public relations" and "stronger advertising and showcasing of Canada's quantum agenda" (NRC 2017: 8). Meanwhile, a report from the Netherlands briefly highlights the need for awareness to avoid a 'quantumphobic' society and enable social debate regarding the ethical, legal, and social aspects of quantum technology (QNL 2019). Further work is needed to expand on this prior research and examine the societal implications and potential public good of these emerging technologies (Roberson et al. 2020).

Instead, the role of expectations for this field has been most visible in the coordination efforts of science and technology actors, creation of strategies, and marshalling of resources. As described in this article, the creation of the term 'quantum technology' has helped define and shaped the momentum of this field even while different terms have worked to shift the focus of researchers in different directions. Now, with quantum technology the subject of substantial attention and investment, is a moment of hopeful, promissory hype and it remains to be seen how this heightened state of expectation progresses in Australia and further afield.

Acknowledgements With thanks to A. White and referees for thoughtful comments and discussion.

Funding The author prepared this manuscript and undertook this research while employed as a CSIRO Future Science Fellowship in Responsible Innovation (2020-2023). This fellowship is jointly funded the Australian Research Council Centre of Excellence for Engineered Quantum Systems (EQUS, CE170100009) and CSIRO's Responsible Innovation Future Science Platform.

Open Access This article is licensed under a Creative Commons Attribution 4.0 International License, which permits use, sharing, adaptation, distribution and reproduction in any medium or format, as long as you give appropriate credit to the original author(s) and the source, provide a link to the Creative Commons licence, and indicate if changes were made. The images or other third party material in this article are included in the article's Creative Commons licence, unless indicated otherwise in a credit line to the material. If material is not included in the article's Creative Commons licence and your intended use is not permitted by statutory regulation or exceeds the permitted use, you will need to obtain permission directly from the copyright holder. To view a copy of this licence, visit http://creativecommons.org/licen ses/by/4.0/. 


\section{References}

Adams, Vincanne, Michelle Murphy, and Adele E. Clarke. 2009. Anticipation: Technoscience, life, affect and temporality. Subjectivity 28: 246-265.

Apreda, Riccardo, Andrea Bonaccorsi, Gualtiero Fantoni, and Donata Gabelloni. 2014. Functions and failures: how to manage technological promises for societal challenges. Technology Analysis \& Strategic Management 26(4): 369-384.

Arribas-Ayllon, Michael, Andrew Bartlett, and Katie Featherstone. 2010. Complexity and accountability: The witches' brew of psychiatric genetics. Social Studies of Science 40(4): 499-524.

Barlösius, Eva. 2018. Begrenzt gewagte Heterodoxie: Originalität ohne Risiko. Eine Studie über

Forschungsanträge. In Heterodoxie. Konzepte, Traditionen, Figuren der Abweichung, eds. M. Schetsche, and I. Schmied-Knittel, 99-116. Köln: Herbert von Harlem.

Barlösius, Eva. 2019. Concepts of originality in the natural science, medical, and engineering disciplines: an analysis of research proposals. Science, Technology, \& Human Values 44(6): 915-937. https:// doi.org/10.1177/0162243918808370.

Bate, Robert T. 1986. The quantum effect device: Tomorrow's transistor. Scientific American. March

Birch, Kean, Les Levidow, and Theo Papaioannou. 2012. Self-fulfilling prophecies of the European Knowledge-Based Bio-Economy: The discursive shaping of institutional and policy frameworks in the bio-pharmaceuticals sector. Journal of the Knowledge Economy 5(1): 1-18.

South China Morning Post. 2018. Is China winning race with US to develop quantum computers?

Borup, Mads, Nik Brown, Kornelia Konrad, and Harro van Lente. 2006. The sociology of expectations in science and technology. Technology Analysis \& Strategic Management 18(3): 285-298.

Brown, Nik. 2000. Organising/disorganising the breakthrough motif: Dolly the cloned ewe meets Astrid the hybrid pig. In Contested Futures: A Sociology of Prospective Science and Technology, eds. Nik Brown, Brian Rappert, and Andrew Webster, 87-110. Aldershot: Ashgate.

Brown, Nik. 2003. Hope against hype-accountability in biopasts, presents and futures. Science Studies 16(2): 3-21.

Bush, Vannevar. 1945. Science-The Endless Frontier. Washington: United States Government Printing Office.

Cagnin, Cristiano, Effie Amanatidou, and Michael Keenan. 2012. Orienting European innovation systems towards grand challenges and the roles that FTA can play. Science and Public Policy 39: 140-152. https://doi.org/10.1093/scipol/scs014.

Coenen, Christopher, and Armin Grunwald. 2017. Responsible research and innovation (RRI) in quantum technology. Ethics Information Technology 19: 277-294.

Connor, Ulla, and Anna Mauranen. 1999. Linguistic analysis of grant proposals: European Union research grants. English for Specific Purposes 18(1): 47-62. https://doi.org/10.1016/S08894906(97)00026-4.

CSIRO. 2019. Quantum Technology Roadmap Discussion Paper. Australia: Commonwealth Scientific and Industrial Research Organisation.

CSIRO. 2020. Growing Australia's Quantum Techology Industry. Australia: Commonwealth Scientific and Industrial Research Organisation.

de Wolf, Ronald. 2017. The potential impact of quantum computers on society. Ethics Information Technology 19: 271-276.

DiVincenzo, David P. 2017. Scientists and citizens: getting to quantum technologies. Ethics Information Technology 19: 247-251.

Dourish, Paul, and Genevieve Bell. 2014. Divining a digital future. Cambridge: MIT Press.

Dowling, Jonathan P., and Gerard Milburn. 2003. Quantum technology: the second quantum revolution. Philosophical Transactions of the Royal Society A 361(1809). https://doi.org/10.1098/rsta. 2003.1227.

Eames, Malcolm, William McDowall, Mike Hodson, and Simon Marvin. 2006. Negotiating contested visions and place-specific expectations of the hydrogen economy. Technology Analysis \& Strategic Management 18(3-4): 361-374. https://doi.org/10.1080/09537320600777127.

EPSRC. 2014. National strategy for quantum technologies, ed. UK National Quantum Technologies Programme. London, UK: Engineering and Physical Sciences Research Council.

EPSRC. 2018. Quantum Technologies Public Dialogue Report: Engineering and Physical Sciences Research Council 
Fujimura, Joan H. 2003. Future Imaginaries: Genome Scientists as Sociocultural Entrepreneurs. In Scientists as Sociocultural Entrepreneurs, eds. Alan H. Goodman, Deborah Heath, and Susan M. Lindee, 176-199. Los Angeles: University of California Press.

Fuller, Steve, and James H. Collier. 2004. Philosophy, Rhetoric, and the End of Knowledge: A New Beginning for Science and Technology Studies. London: Routledge.

Gartner. 2015. Gartner Hype Cycle. Research Methodologies. http://www.gartner.com.ezproxy.libra ry.uq.edu.au/technology/research/methodologies/hype-cycle.jsp. Accessed 3 March 2015.

Geels, Frank W., and Wim A. Smit. 2000. Lessons from failed technology futures: Potholes in the road to the future. In Contested futures: A sociology of prospective techno-science, eds. Nik Brown, Brian Rappert, and Andrew Webster, 129-156. Aldershot: Ashgate.

Gibney, Elizabeth. 2019. Quantum gold rush: the private funding pouring into quantum start-ups. Nature.

Greenberg, Daniel S. 2001. Science, Money, and Politics. Chicago, USA: University of Chicago Press.

Gross, Alan. 1994. The roles of rhetoric in the public understanding of science. Public Understanding of Science 3: 3-23.

Guston, David H. 2012. The Pumpkin or the Tiger? Michael Polanyi, Frederick Soddy, and Anticipating Emerging Technologies. Minerva 50(3): 363-379. https://doi.org/10.1007/s1102-012-9204-8.

Hellsten, Iina, and Brigitte Nerlich. 2008. Genetics and genomics: The politics and ethics of metaphorical framing. First edition. Handbook of Public Communication of Science and Technology. London and New York: Routledge.

Horst, Maja. 2007. Public expectations of gene therapy: Scientific futures and their performative effects on scientific citizenship. Science, Technology, \& Human Values 32(2): 150-171.

Jasanoff, Sheila, and Sang-Hyun. Kim. 2009. Containing the Atom: Sociotechnical Imaginaries and Nuclear Power in the United States and South Korea. Minerva 47(2): 119-146. https://doi.org/10. 1007/s11024-009-9124-4.

Jasanoff, Sheila, and Sang-Hyun. Kim. 2015. Dreamscapes of Modernity: Sociotechnical Imaginaries and the Fabrication of Power. Chicago, IL: University of Chicago Press.

Joly, Pierre-Benoit. 2010. On the Economics of Techno-scientific Promises. In Debordements. Melanges offerts a Michel Callon, eds. Madeleine Akrich, Yannick Barthe, Fabian Muniesa, and Philippe Mustar, 203-221. Paris: Presse des Mines.

Konrad, Kornelia, Harro van Lente, Christopher Groves, and Cynthia Selin. 2017. Performing and Governing the Future in Science and Technology. In The Handbook of Science and Technology Studies, eds. Ulrike Felt, Rayvon Fouche, Clark A. Miller, and Laurel Smith-Doerr, 465-493. Cambridge, United States of America: The MIT Press.

Laudel, Grit. 2006. The art of getting funded: How scientists adapt to their funding conditions. Science and Public Policy 33(7): 489-504. https://doi.org/10.3152/147154306781778777.

Milburn, Gerard. 1997. Schrodinger's machines: The quantum technology reshaping everyday life. New York: WH Freeman \& Co.

MIT Technology Review. 2019. How a quantum computer could break 2048-bit RSA encryption in 8 hours.

Moller, Matthias, and Cornelius Vuik. 2017. On the impact of quantum computing technology on future developments in high-performance scientific computing. Ethics Information Technology 19: 253269. https://doi.org/10.1007/s10676-017-9438-0.

Myers, Greg. 1990. Writing biology: texts in the social construction of scientific knowledge. Madison: University of Wisconsin Press.

Nerlich, Brigitte. 2009. Breakthroughs and Disasters: The (Ethical) Use of Future-Oriented Metaphors in Science Communication. In Communicating Biological Sciences: Ethical and Metaphorical Dimensions, eds. Brigitte Nerlich, Richard Elliott, and Brendon Larson. London: Routledge.

Nerlich, Brigitte, Richard Elliott, and Brendon Larson. 2009. Communicating Biological Sciences: Ethical and Metaphorical Dimensions. England: Ashgate Publishing Company.

Nerlich, Brigitte, and Carmen McLeod. 2016. The dilemma of raising awareness "responsibly." $E M B O$ Reports 17: 4. https://doi.org/10.15252/embr.201541853.

NOKIA Bell Labs. 2019. 1956 Nobel Prize in Physics: The Transistor. https://www.bell-labs.com/about/ recognition/1956-transistor/. Accessed 22 June 2020.

NRC. 2017. Quantum Canada: Survey overview. Canada: National Research Council.

Petersen, Alan, Megan Munsie, Claire Tanner, Casimir MacGregor, and Jane Brophy. 2017. Stem Cell Tourisms and the Political Economy of Hope. London: Palgrave Macmillan UK. 
Philipps, Axel, and Leonie Weißenborn. 2019. Unconventional ideas conventionally arranged: a study of grant proposals for expectional research. Social Studies of Science 49(6): 884-897. https://doi.org/ $10.1177 / 0306312719857156$.

Ploeger, Joanna S. 2002. The art of science at Fermi National Accelerator Laboratory: The rhetoric of aesthetics and humanism in the national laboratory system in the late 1960s. History and Technology: An International Journal 18(1): 23-49.

QNL. 2019. National Agenda for Quantum Technology. The Netherlands: Quantum Delta Nederland.

Radford, Tim. 2009. A Workbench View of Science Communication and Metaphor. In Communicating Biological Sciences: Ethical and Metaphorical Dimensions, eds. Brigitte Nerlich, Richard Elliott, and Brendon Larson, 145-152. London: Routledge.

Rip, Arie. 2010. De Facto Governance of Nanotechnologies. In Dimensions of Technology Regulation, eds. Morag Goodwin, Bert-Jaap Koops, and Ronald Leenes, 285-308. Nijmegen: Wolf Legal Publishers.

Ritter, Joshua. R. 2010. Recovering Hyperbole: Re-Imagining the Limits of Rhetoric for an Age of Excess. Georgia State University.

Roberson, Tara. 2020. Can hype be a force for good? Inviting unexpected engagement with science and technology futures. Public Understanding of Science (OnlineFirst). https://doi.org/10.1177/09636 62520923109.

Roberson, Tara, Joan Leach, and Sujatha Raman. 2020. Talking about public good for the second quantum revolution: Analysing quantum technology narratives in the context of national strategies. Quantum Science and Technology. https://doi.org/10.1088/2058-9565/abc5ab.

Roberson, Tara, and Andrew G. White. 2019. Charting the Australian quantum landscape. Quantum Science and Technology 4: 2. https://doi.org/10.1088/2058-9565/ab02b4.

Schyfter, Pablo, and Jane Calvert. 2015. Intentions, expectations, and institutions: engineering the future of synthetic biology in the USA and the UK. Science as Culture 24(4): 359-383. https://doi.org/10. 1080/09505431.2015.1037827.

Serrano Velarde, Kathia. 2018. The Way We Ask for Money...The Emergence and Institutionalization of Grant Writing Practices in Academia. Minerva 56(1): 85-107. https://doi.org/10.1007/ s11024-018-9346-4.

Smith, Andrew E., and Michael S. Humphreys. 2006. Evaluation of unsupervised semantic mapping of natural language with Leximancer concept mapping. Behavior Research Methods 38(2): 262-279. https://doi.org/10.3758/BF03192778.

te Kulve, Haico, Kornelia Konrad, Carla Alvial Palavicino, and Bart Walhout. 2013. Context matters: promises and concerns regarding nanotechnologies for water and food applications. NanoEthics 7(1): 17-27. https://doi.org/10.1007/s11569-013-0168-4.

Tutton, Richard. 2011. Promising pessimism: Reading the futures to be avoided in biotech. Social Studies of Science 41(3): 411-429. https://doi.org/10.1177/0306312710397398.

USA. 2018. National Quantum Initiative Act. In HR6227, ed. House of Representatives.

van Lente, Harro. 1993. Promising Technology: The Dynamics of Expectations in Technological Developments, PhD Dissertation. University of Twente.

van Vuuren, Kitty, Dan Angus, and Susan Ward. 2014. Clean energy futures and place-based responses: a comparison to letters-to-the-editor in two Australian regions. Communication, Politics and Culture 47(2): 17-34.

Williams, Robin. 2006. Compressed foresight and narrative bias: Pitfalls in assessing high technology futures. Science as Culture 15(4): 327-348. https://doi.org/10.1080/09505430601022668.

Winner, Langdon. 1980. Do Artifacts Have Politics? Daedalus 1 (Modern Technology: Problem or Opportunity?), pp 121-136.

Publisher's Note Springer Nature remains neutral with regard to jurisdictional claims in published maps and institutional affiliations. 